\title{
Sensitivity of Cadmium Sulfide under the Influence of Both Substrate Temperature and Gas Operation
}

\author{
Ehssan Salah Hassan ${ }^{1}$, Zaid Saud Razzaq ${ }^{2}$, Huda Ashur Shati Qutbi ${ }^{3}$, Sami Salman Chiad ${ }^{4}$, \\ Nadir Fadhil Habubi ${ }^{4}$, Khalid Haneen Abass ${ }^{5}$ \\ ${ }^{1}$ Department of Physics, College of Science, Mustansiriyah University, Baghdad, Iraq. \\ ${ }^{2}$ Department of Sciences, Faculty of Basic Education, Al-Muthanna University, Al Muthanna, Iraq. \\ ${ }^{3}$ Physiology and Medical Physics Department, College of Medicine, University of Wasit, Wasit, Iraq. \\ ${ }^{4}$ Department of Physics, College of Education, Mustansiriyah University, Baghdad, Iraq. \\ ${ }^{5}$ Department of Physics, College of Education for Pure Sciences, University of Babylon, Iraq. \\ Corresponding author. E-mail: pure.khalid.haneen@uobabylon.edu.iq
}

Received: May 4, 2021; Accepted: Dec. 2, 202I; Published: Dec. 16, 2021

Citation: Ehssan Salah Hassan, Zaid Saud Razzaq, Huda Ashur Shati Qutbi, Sami Salman Chiad, Nadir Fadhil Habubi, and Khalid Haneen Abass,Sensitivity of Cadmium Sulfide under the Influence of Both Substrate Temperature and Gas Operation. Nano Biomed. Eng., 202I, $13(4)$ : 425-432. DOI: 10.5101/nbe.v13i4.p425-432.

\begin{abstract}
The importance of this research is to study the effect of changing the temperature at the same time on each of the prepared samples and during the gas sensing processes, the effects of substrate temperature $T_{\mathrm{s}}$ were investigated after precipitation by the microstructural and optical characteristics of cadmium sulfide using thermal spraying method with different temperatures of $(300,400$, and 500$){ }^{\circ} \mathrm{C}$. The structural investigations of these films were studied, showing that the increases in substrate temperature were shown cubic and hexagonal phases according to ICDD card no. (21-0929) and (43-0989). The dramatic change occurred at $500{ }^{\circ} \mathrm{C}$ in changing the phase from hexagonal to a cubic structure. XRD exhibits a dominant plane at (200) for different substrate temperatures. Optical transmittance, absorption coefficient, and energy gap values were calculated by UV/VIS spectrophotometer. These results showed that the band gap values decreased with increasing substrate temperature. The gas sensitivity was tested for $\mathrm{NO}_{2}$ gas at several working temperatures from $175^{\circ} \mathrm{C}$ to $250{ }^{\circ} \mathrm{C}$, and various gas concentrations from $150 \mathrm{ppm}$ to $200 \mathrm{ppm}$ and found that the sensitivity increase with increasing both the operating temperature and gas concentration for a $\mathrm{T}_{\mathrm{s}}$ at $500{ }^{\circ} \mathrm{C}$ which offer also the best crystallization the best sensitivity at an operating temperature of $175^{\circ} \mathrm{C}$ is $75 \%$ at a gas concentration of 150 ppm.
\end{abstract}

$\overline{\text { Keywords: SPM, Substrate temperature, Hexagonal phase, Cubic phase, Sensitivity, Recovery and }}$ response time

\section{Introduction}

The optical and structural characteristics of cadmium sulfide CdS films grown by chemical spraying method SPM is dependent on several factors, such as material concentration involved in the reaction [1], the PH [2], the thickness of the resulting deposited film [3]. In chemical spraying processes, film development processes are performed either by condensing ion with ion, or by adsorbing the colloidal solution from the surface of the substrate [4]. Many methods are used for the preparation of cadmium sulfide, including vacuum thermal evaporation [5], RF and DC sputtering [6], screen printing [7], chemical bath deposition [8], Spin coated [9], hot injection method [10], but among these methods chemical spraying was more affordable and 
easy to prepare thin films from chemical reactions in addition the grown films were homogeneous and high adhesion [11-13]. Optical characteristics like permeability, absorption and energy gap values are important for gas sensing applications [14]. Gas sensor is very important applications in science in which cadmium sulfate is used mainly single or polycrystalline. Cadmium sulfide has been widely used in factories, scientific laboratories, mines or houses, for its unique electrical and optical properties in providing high efficiency and long running life due to their stable performance, high-efficiency and low cost, and were utilized for large area terrestrial applications [15]. In the present study, $\mathrm{NO}_{2}$ is considered as a dangerous gas that is emitted from the burnings of car engines exhaust, plants, furnaces and home heaters [16]. Thus, there is a high importance in developing sensors that are small in size, quick in response, with long-lifetime and adequate sensitivity to detect $\mathrm{NO}_{2}$ even in low concentrations [17]. CdS films as a sensor to study the interaction of oxygen gas [18]. Study the performance of CdS on $\mathrm{H}_{2} \mathrm{~S}$ gas [19]. Alcohol gas by $\mathrm{CdS}$ sensor [20]. CdS films to detect $\mathrm{NO}_{2}$ gas [21]. The optical, structural and sensing characteristics of CdS were examined and the results are discussed.

\section{Experimental}

Cadmium sulfide films are prepared utilizing chemical spray pyrolysis technique. $\mathrm{CdCl}_{2}$ supplied from (BDH chemical) was used as a source of cadmium whereas theories $\left(\mathrm{NH}_{2} \mathrm{CSNH}_{2}\right)$ supplied from (BDH Chemicals) was employed to obtain sulfur on the saturated solution $\mathrm{CdCl}_{2}$ with deionized water in 1:1 volume proportion. This solution was sprayed onto the preheated substrate at a different temperature of $300{ }^{\circ} \mathrm{C}, 400{ }^{\circ} \mathrm{C}$ and $500{ }^{\circ} \mathrm{C}$. The optimum condition to obtain homogenous thin film free from any notable crack arrives at the following; Nitrogen was the carrier gas, distance between nozzle and substrate was $28.0 \mathrm{~cm}$, the spray rate was $8 \mathrm{~mL} / \mathrm{min}$. CdS thin film thickness is measured by gravimetric method. All as deposited CdS thin films have a thickness of $300 \pm$ $30 \mathrm{~nm}$. UV. A UV-Visible double spectrophotometer in wavelength range of (300 nm-900 nm) was used to determine the value of transmittance and absorbance spectra.

\section{Result and discussion Structural and morphological}

Fig. 1 exhibits the XRD patterns of CdS films. CdS films at low substrate temperature $300{ }^{\circ} \mathrm{C}$ and $400{ }^{\circ} \mathrm{C}$ exist in polycrystalline hexagonal structure according to ICDD no. 10-0454 [20]. The preferred reflection at $300{ }^{\circ} \mathrm{C}$ and $400{ }^{\circ} \mathrm{C}$ is $(020)$ plane at $2 \theta=36.34^{\circ}$ for hexagonal phase. Besides, many secondary reflections at (001), (110), (021), (121), (102) and (220) for

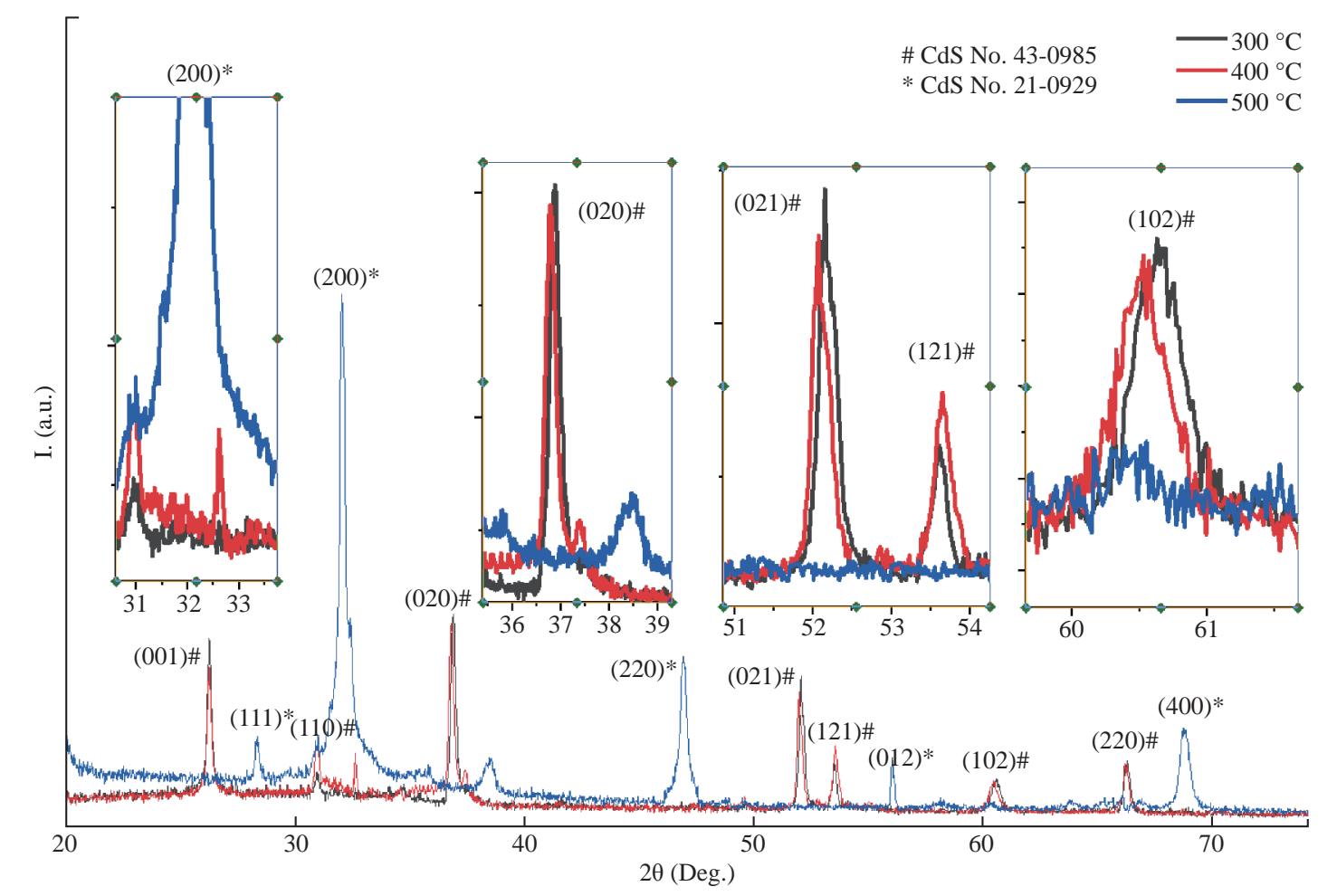

Fig. 1 XRD pattern of CdS with different substrate temperatures by SPM. 
hexagonal phase at angles $2 \theta=26.18^{\circ}, 31.60^{\circ}, 45.32^{\circ}$, $53.12^{\circ}, 60^{\circ}$ and $66.31^{\circ}$ were observed. At the substrate temperature of $500{ }^{\circ} \mathrm{C}$ the preferred reflection was changing from (020) to (200) plane at $2 \theta=32.43^{\circ}$ and to the cubic according to ICDD no. 06-0314. This level makeover from hexagonal to cubic is formerly identified for chemically deposited CdS films [23-24]. It is worth noting here that the temperature $400{ }^{\circ} \mathrm{C}$ represented the turning point from the cubic phase to the hexagonal at the reflection of (200) at the angle of $2 \theta=32.43^{\circ}$ and as shown in the inset figures attached to Fig. 1 with several secondary reflections at (111), (220) and (400) at angles $2 \theta=28.31^{\circ}, 47.87^{\circ}$ and $68.12^{\circ}$. This level makeover from hexagonal to cubic is formerly identified for chemically deposited CdS films. The regular $(200)$ reflection at $2 \theta=32.43^{\circ}$ recycled to analyze the crystallite sizes from the XRD decoration, as anticipated, growing the substrate temperature effects an improvement of Bragg reflections, indicating an increase in film's crystallinity. Also, crystallite size was conducted with the use of Scherer's formula [25]:

$\mathrm{D}=\mathrm{k} \lambda /(\beta \cos \theta)$

In which $\mathrm{K}$ is the shape factor, $\beta$ representing fullwidth at the half maximum FWHM related to Bragg reflection within considerations in radians, $\lambda$ is the wavelength of X-ray, and $\theta$ representing Bragg angle. Equation (1) is applied for calculating the crystallite sizes (D) with the use of $K=0.9$, while the lattice parameter values are calculated utilizing equations [25]:

$\mathrm{a}=\mathrm{d}\left(\mathrm{h}^{2}+\mathrm{k}^{2}+\mathrm{l}^{2}\right)^{1 / 2}$

$1 / d^{2}=\left[4\left(h^{2}+h k+k^{2}\right) /\left(3 a^{2}\right)\right]+1^{2} / c^{2}$

The crystallite size that is related to $\mathrm{T}_{\mathrm{s}}$ of $\left(300^{\circ} \mathrm{C}\right)$ is $20.42 \mathrm{~nm}$ and was increase to $(26 \mathrm{~nm})$ with the increase in $\mathrm{T}_{\mathrm{s}}$ to $500{ }^{\circ} \mathrm{C}$. The microstrain $(\varepsilon)$ is obtained by Equation (4) resulted throughout the film growth and is going to be elevated from compression or stretching in a lattice. Besides, $\varepsilon$ reduction resulting from changing the atom's displacement in terms of their reference lattice position. Fig 2(b) is showing that there will be a decrease in $\varepsilon$ with the increase in $\mathrm{T}_{\mathrm{s}}$, which might be caused by the increase in film's crystallinity. Besides, the dislocation density $(\delta)$ can be defined as a number of dislocation per unit volume utilizing Equation (5). Fig 2(c) is showing a decrease in dislocation density with the increase in substrate $T_{s}$. The results related to $\varepsilon$ Eq. (4) as well as the $\delta$ values are indicated in Table 1 [26]:

$\varepsilon=(\beta \cos \theta) / 4$

$\delta=1 / \mathrm{D}^{2}$

Table 1 lists the calculated structural parameters. where the application of Gaussian for a process of Fit for reflection preferred as shown in Fig. 2(d) and (e), which gives high precision values. Fig. 3 shows Energy Dispersive Spectrometry EDS, which gives a precise illustration of the elements that make up the membrane by weight ratios of $w t \%$ and atomic atoms at $\%$. From
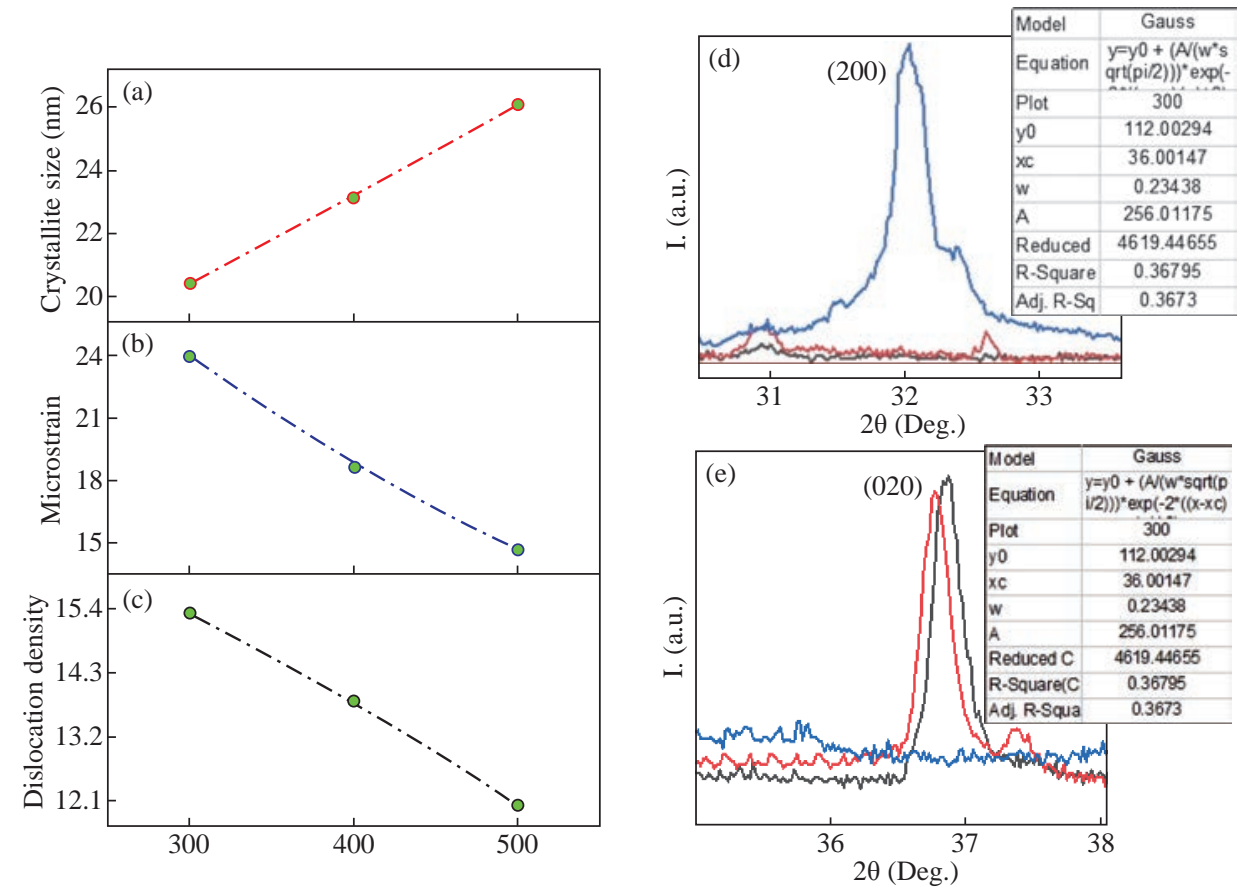

Fig. 2 The variation of (a) size of the crystallite, (b) micro-strain and (c) density of dislocation (d) and (e) FWHM for the preferred diffraction CdS films with the substrate temperature. 


\begin{tabular}{|c|c|c|c|c|c|c|c|c|}
\hline $\mathrm{T}_{\mathrm{s}}\left({ }^{\circ} \mathrm{C}\right)$ & $\begin{array}{l}\text { (hkl) } \\
\text { Plane }\end{array}$ & $\begin{array}{l}\text { 2theta } \\
\text { (Deg.) }\end{array}$ & \multicolumn{2}{|c|}{$\begin{array}{c}\text { Lattice } \\
\text { constant }(\AA)\end{array}$} & $\begin{array}{l}\text { FWHM } \\
\text { (Rad) }\end{array}$ & $\begin{array}{c}\text { Crystallite } \\
\text { size D (nm) }\end{array}$ & $\begin{array}{c}\text { Micro-strain } \\
\left(\text { line }^{-2} \cdot \mathrm{m}^{-1}\right) \times 10^{-3}\end{array}$ & $\begin{array}{l}\text { Density of Dislocation } \\
(\delta)\left(\text { line } \cdot \mathrm{m}^{-2}\right) \times 10^{15}\end{array}$ \\
\hline 300 & (020) & 36.34 & $\begin{array}{c}\mathrm{a} \\
3.55\end{array}$ & $\begin{array}{c}\text { c } \\
3.67\end{array}$ & 0.37 & 20.42 & 1.532 & 2.397 \\
\hline 400 & (020) & 35.87 & $\begin{array}{c}\mathrm{a} \\
3.56\end{array}$ & $\begin{array}{c}\text { c } \\
3.65\end{array}$ & 0.33 & 23.140 & 1.381 & 1.867 \\
\hline 500 & (200) & 32.43 & & & 0.29 & 26.08 & 1.202 & 1.469 \\
\hline
\end{tabular}

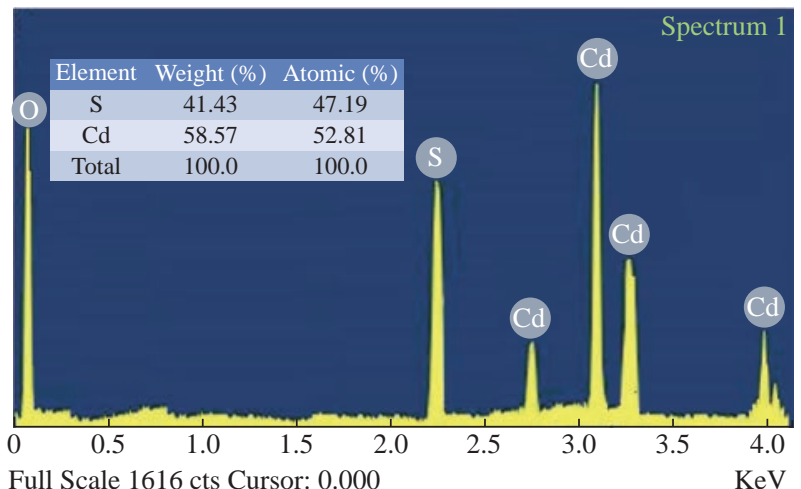

Fig. 3 Energy Dispersive Spectrometry for the preferred diffraction CdS films with the substrate temperature.

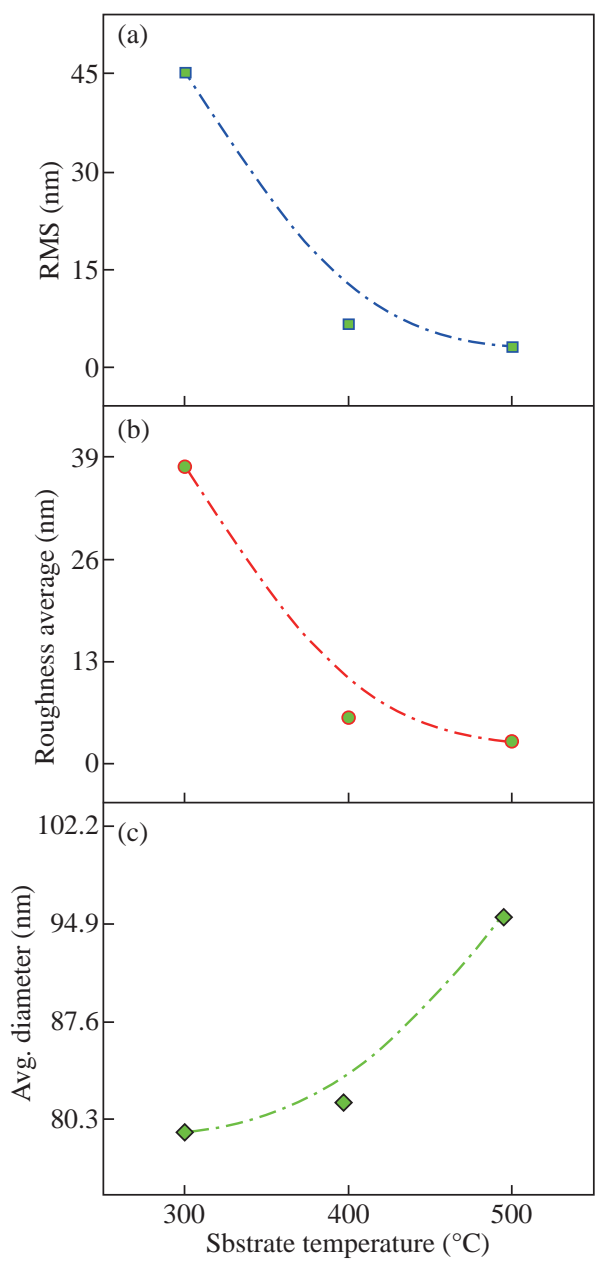

the figure we note the emission spectrum Oxygen spectrum $(\mathrm{K} \alpha=0.50 \mathrm{keV}$ and the cadmium spectrum at $\mathrm{K} \alpha=2.75 \mathrm{keV}, \mathrm{L} \alpha=3.1 \mathrm{keV}, \mathrm{M} \alpha=3.31 \mathrm{keV}$, and $\mathrm{M} \alpha$ $=3.99 \mathrm{keV}$. And the sulfur spectrum of $\mathrm{K} \alpha=2.52 \mathrm{eV}$.

The AFM micrographs of CdS with different substrate temperature films (Fig. 4) exhibits that the grain distribution is not even over all areas. However, Fig. 4 shows the presence of smooth and bright regions. In Fig. 4(f) we notice that the average diameter is larger and resembles the vertical growth and more closely the density of nanoparticles on the shape of vertical rods on the surface of the nanostructured film
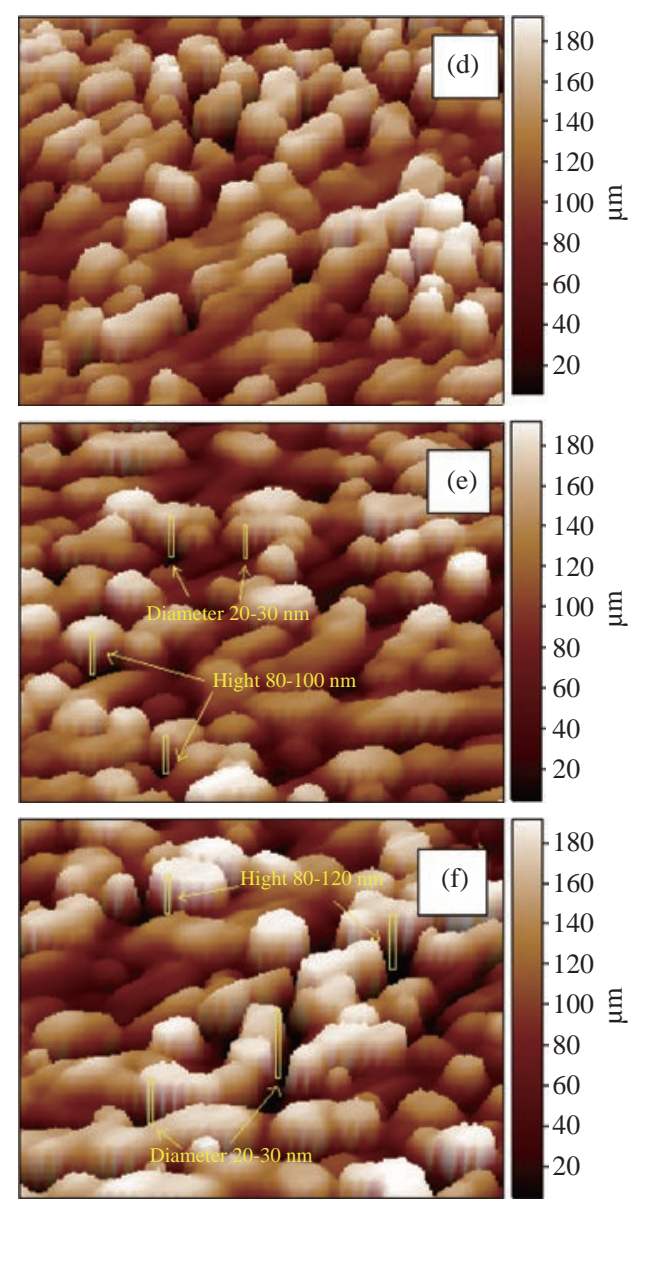

Fig. 4 AFM, 3-D image of CdS nanostructured film (a)-(c) RMS, Roughness Average and Avg. Diameter, (d) $300{ }^{\circ} \mathrm{C}$, (e) $400{ }^{\circ} \mathrm{C}$ and (f) $500{ }^{\circ} \mathrm{C}$. 
with an average diameter of (20-30) $\mathrm{nm}$ and the height (80-120) nm compared to the Fig. 4(d) in which the bright areas are (with little growth) with less intensity or in Fig. 4(e) as the substrate temperature Increasing from $300{ }^{\circ} \mathrm{C}$ to $400{ }^{\circ} \mathrm{C}$. The reason for the difference in crystallite size that calculated from X-Ray diffraction pattern and the mean grain size that measured by AFM is that the XRD deals with wavelengths that do not exceed the $\lambda=1.5432 \AA$, that is, it measures units at the level of the unit cell while the AFM deal with a group of unit cells and grain boundary, which consists of one atom or more. As indicated in Figures (4(a), (b) and (c)) the rate of average diameter will be increased with the increase in substrate temperature accompanied with RMS as well as roughness average that decreases when the substrate temperature increase.

\section{Transmittance and absorption coefficient}

Fig. 5 represents the transmittance spectra values as the function of wavelength of cadmium sulfide CdS deposited by chemical spray pyrolysis. From transmittance spectra, values of the transmittance decrease with the increase of the substrate temperature where it was $90 \%$ at $\mathrm{T}_{\mathrm{s}}$ of $300{ }^{\circ} \mathrm{C}$ and decreased to $86 \%$ and then $83 \%$ with a $\mathrm{T}_{\mathrm{s}}$ rise to $400{ }^{\circ} \mathrm{C}$ and 500 ${ }^{\circ} \mathrm{C}$ respectively. It may be due to changes in the structural and morphological characteristics of surface transformation in the phase from the hexagonal to the cubic, and the increase in crystal size. Fig. 5(b) representing the values related to absorption coefficient deducing that the band gap type was direct since such values were more than $10^{5}$ [27]. Also, their dependence in drawing the relations between the values of photon energy (hv) as well as $(\alpha h v)^{2}$ as in Fig. 5(c), in which the band gap value was evaluated via extrapolation of the straight line of the plot of $(\alpha h v)^{2}$ vs. the energy of the photon, which is observed to decrease as the base temperature increases.

\section{Gas sensing properties}

The gas sensing characteristics of nanostructured $\mathrm{CdS}$ films of that prepared at $500{ }^{\circ} \mathrm{C}$ for a variety
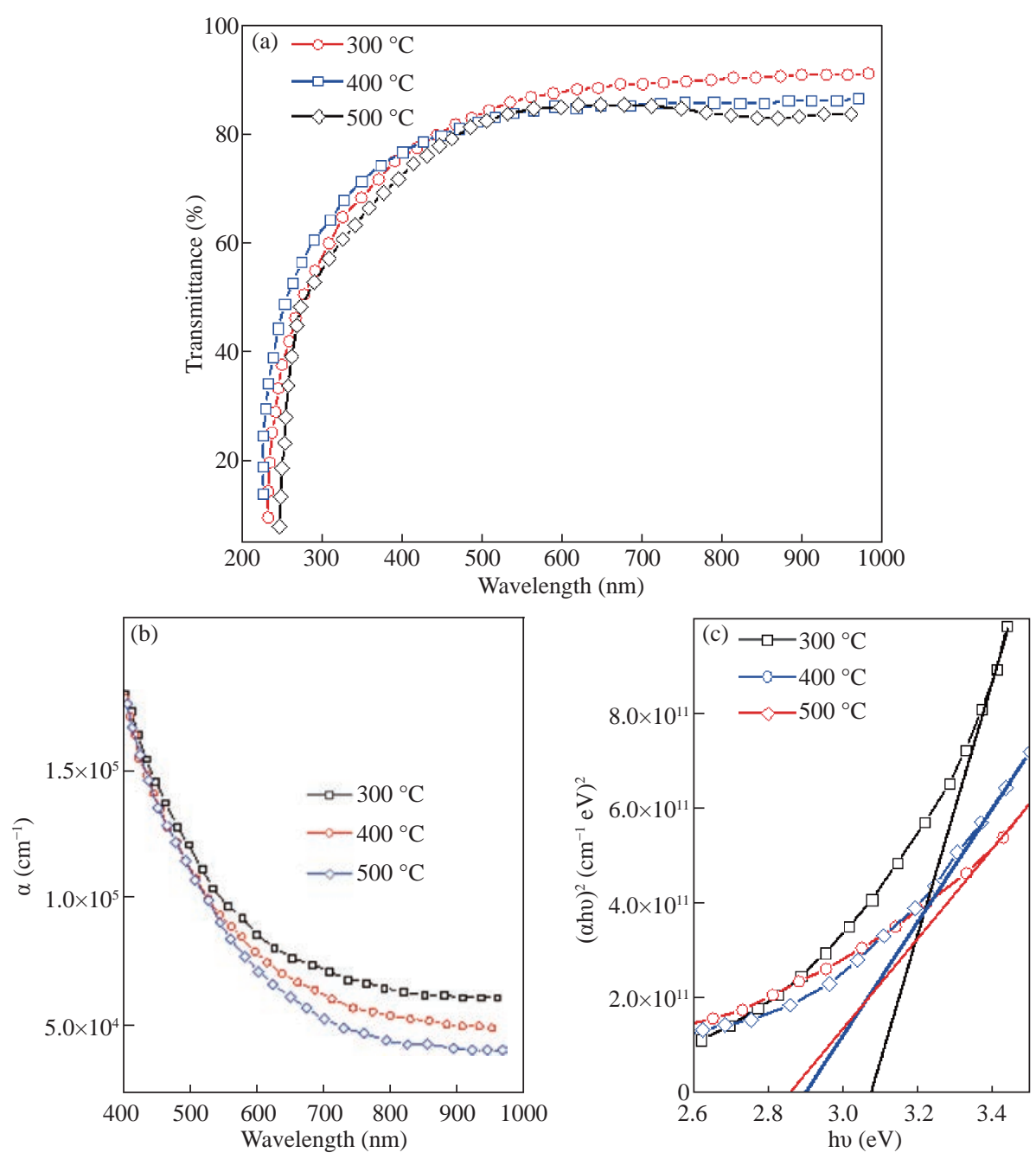

Fig. 5 (a) Transmittance as function to the wave-length for CdS by (SPM). (b) Absorption coefficient. (c) Band gap. 
of gas concentrations of $\mathrm{NO}_{2}$ as oxidized gas are examined as a function of various operation time. Fig. 6(a) is showing the dynamic resistance changes related to the nanostructured CdS films which are prepared at a temperature of $500{ }^{\circ} \mathrm{C}$ through (SPM), exposure to various $\mathrm{NO}_{2}$ gas concentrations (150, 200 as well as 250) $\mathrm{ppm}$. It is indicated that the lowest resistance is for samples at $175^{\circ} \mathrm{C}$ and increasing due to the highest roughness acquired from the AFM analysis as well as the n-type semiconductor performance [28] also the film's resistance will be increased with an increase in $\mathrm{NO}_{2}$ concentrations in the chamber [29], this might be justified as electrons have been taken from ionized donors via conduction band, also the density which is related to majority charge carriers (electrons) at gas film surface interface was reduced. In addition, this will result in increasing the potential barrier for electrons with an increase in oxygen ion density on the surface. Also, the potential barrier and depletion layer are leading to an increase in the value of electrical resistivity, such value is depending on the concentrations of the adsorbed oxygen ions on the surface [29].

The sensitivity might be estimated from Equation (6) and plotted as a function of operating temperature as seen in Fig. 6(c).

ensitivity $=\Delta R / R_{g}=\left|\left(R_{g}-R_{a}\right) / R_{g}\right| \times 100 \%$

The sensitivity percentage value of CdS films of $\mathrm{NO}_{2}$ gas with various operating temperatures is increased with the increase in film's operating temperatures and highest value of sensitivity has been $75 \%$ for $250 \mathrm{ppm}$ gas concentrations of $\mathrm{NO}_{2}$ acquired from the film of $500{ }^{\circ} \mathrm{C}$ substrate temperature at operation temperature $250{ }^{\circ} \mathrm{C}$. Besides, the sensitivity related to metal oxide semiconductor sensor was majorly specified via interactions between sensor's surface and the target gas [30]. Interactions between sensor surface and adsorbed gases is stronger as the surface area of materials showed in AFM measurements becomes greater. Figures 6(d) and 6(e) show the response time as well as recovery time, respectively, which might be directly estimated from Fig. 5(a), and plotted as a function of substrate temperature. Fig. 6(d) is showing the
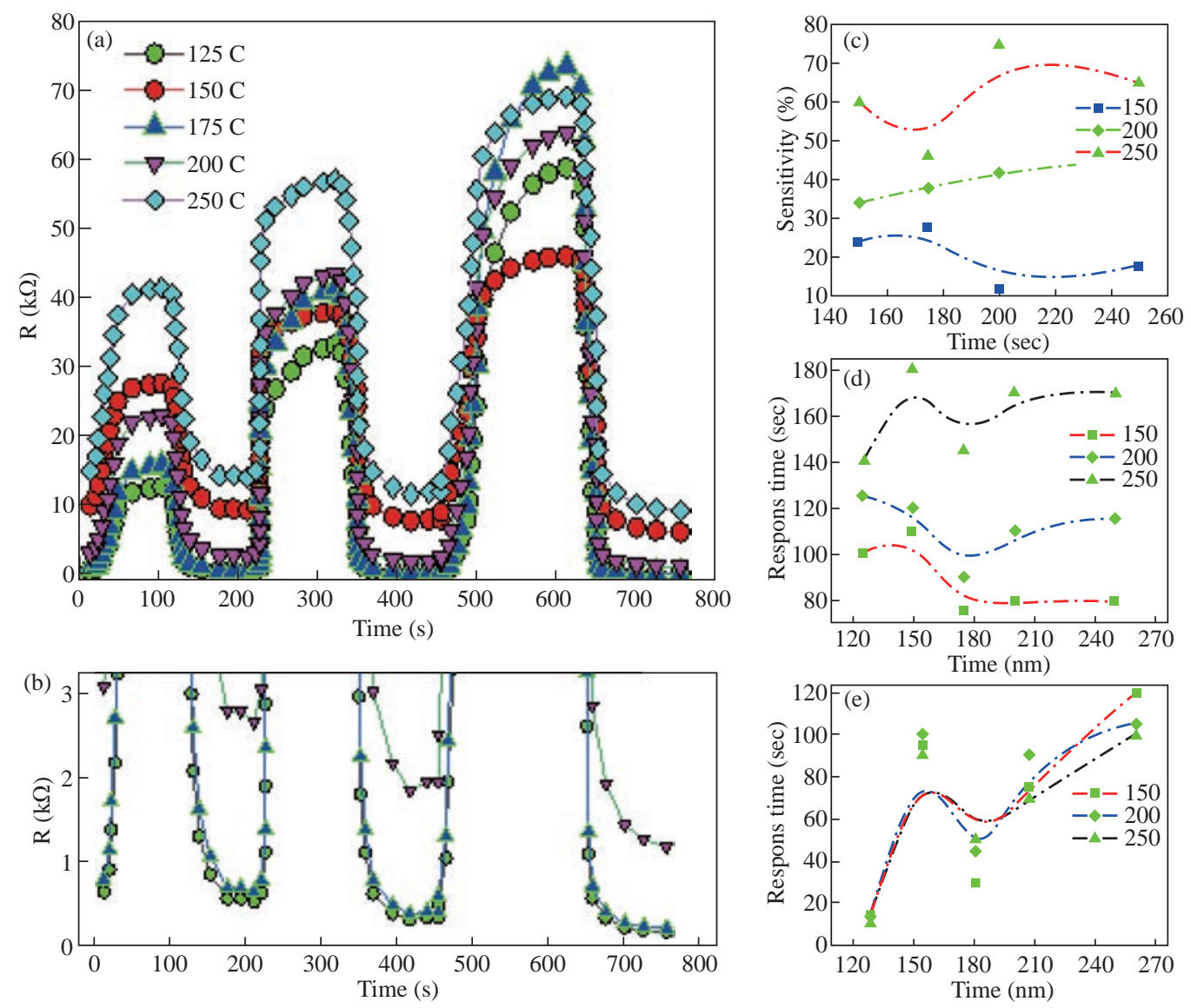

Fig. 6 (a) Dynamic Resistance Change of CdS Film at a substrate temperature of $500{ }^{\circ} \mathrm{C}$ for Various $\mathrm{NO}_{2}$ Gas Concentrations and Various Operating Temperatures. (b) The clip is magnified with small values of resistance and relative to the X-Axis. (c) Sensitivity as a function to substrate temperature. (d) Recovery time as a substrate temperature function, (e) Response time as a function of substrate temperature. 
response time, which is decreasing from (15 to about 120) sec. The increase in substrate temperature could be attributed to the large availability related to vacant sites on the thin films for gas adsorption [31]. While Fig. 6(e) shows a slight decrease in the range that does not exceed 20 seconds for all samples. As the substrate temperature increases, thus increasing because of the sensor's saturation via target gas, also the variations in the structural characteristics might occur through operating temperature.

\section{Conclusions}

The films were prepared within various substrate temperatures, it is indicated that the films are polycrystalline with hexagonal phase at a temperature of $300{ }^{\circ} \mathrm{C}$ and start a very simple change at $400{ }^{\circ} \mathrm{C}$, but at $500{ }^{\circ} \mathrm{C}$ of substrate temperature turns from the hexagonal to the cubic phase $100 \%$ and the prevailing orientation changes from (020) plane to (200) plane and increased particle size and improved crystallization. The selected model for the measurement of the gas sensor at the substrate temperature $500{ }^{\circ} \mathrm{C}$ was the best sensitivity at an operating temperature of $175{ }^{\circ} \mathrm{C}$ is $75 \%$ at a gas concentration of $150 \mathrm{ppm}$. The selected nanostructured films were effective with the little concentrations of the target gas.

\section{Acknowledgments}

The author would thank Mustansiriyah University (www. uomustansiriyah.edu.iq), for their support in this work.

\section{List of Abbreviations}

XRD: X-Ray Diffraction

\section{$\mathrm{T}_{\mathrm{s}}$ : Substrate Temperature}

ICDD: International Centre for Diffraction Data

UV/VIS: Ultraviolet and Visible light spectrophotometer

$\mathrm{NO}_{2}$ : Nitrogen Dioxide gas

ppm: Part Per Million

SPM; Spray Pyrolysis Method

CdS: Cadmium Sulfide

RF: Radio Frequency
DC: Direct Current Sputtering

AFM; Atomic Force Microscopy

RMS: Root Mine Square

$\mathrm{R}_{\mathrm{a}}$ : Resistance of air

$\mathrm{R}_{\mathrm{g}}$ : resistance of gas

\section{Conflict of Interests}

The authors declare that no competing interest exists.

\section{References}

[1] M.S. Sivakumar, Structural, optical and magnetic properties of $\mathrm{Ba}$ and $\mathrm{Ni}$ doped $\mathrm{CdS}$ thin films prepared by the spray pyrolysis method, Journal of Materials Science: Materials in Electronics, 2017, 28(17): 12432-12439.

[2] A. Kerimova, E. Bagiyev, E. Aliyeva, et al., Nanostructured CdS thin films deposited by spray pyrolysis method, Phys. Status Solidi C, 2017: 1600144.

[3] M.H. Diwan, Effect of Film thickness on Optical and Structural Properties of CdS Thin Films prepared by spray pyrolysis. Diyala Jou. for Pure Sci. 2014. 10(2).

[4] A. Hasnat, J. Podder, Effect of Annealing Temperature on Structural, Optical and Electrical Properties of Pure CdS Thin Films Deposited by Spray Pyrolysis Technique. Advances in Materials Physics and Chemistry, 2012.

[5] M. H. Mustafa, Jou. Esentiol Edu. College, 2015, 21: 88.

[6] F. Liscoa, P. M. Kaminskia, A. Abbasa, et al., Walls, The structural properties of CdS deposited by chemical bath deposition and pulsed direct current magnetron sputtering. 2015, 582(1): 323-327.

[7] L. Yudan, S. Jie; C. Rui, et al., Facile synthesis of mixedphase cobalt sulfide counter electrodes for efficient dye sensitized solar cells. Journal of Materials Science: Materials in Electronics, 2015, 26(1): 42-48.

[8] T. Nakanish, Properties of chemical bath deposited CdS thin films. 35(11): 171-178.

[9] G.K. Rahane, S.B. Jathar, S.R. Rondiya, et al., Photoelectrochemical Investigation on the Cadmium Sulfide (CdS) Thin Films Prepared Using Spin Coating Technique. ES Mater. Manuf., 2021, 11: 57-64.

[10] Md.F. Rahman, Md.M. Alam Moon, Md.H. Ali, et al., A systematic study of how annealing conditions lead to the application-based microstructural, crystallographic, morphological, and optical features of spin-coated CdS thin-films. Optical Materials, 2021: 111136.

[11] B. Piccione, R. Agarwal, Y. Jung, et al, Size-dependent chemical transformation, structural phase-change, and optical properties of nanowires, 2013, 93(17): 2089-2121.

[12] E.S. Hassan, T.H. Mubarak, S.S. Chiad, et al., Physical Properties of indium doped Cadmium sulfide thin films prepared by (SPT). Journal of Physics: Conference Series, 2019, 1294(2): 022008.

[13] E.S. Hassan, D.M. Khudhair, S.K. Muhammad, et al., Structural and Optical Properties of Sprayed Ba Doped CdS Nanostructure Thin Films. Journal of Physics: Conference Series, 2020, 1660(1).

[14] R.S. Meshram, B.M. Suryavanshi, R.M. Thombre, Structural and optical properties of CdS thin films obtained by spray pyrolysis. Advances in Applied Science Research, 2012, 3(3): 1563-1571. 
[15] M.G. Vijaya, structural, optical and electrical studies on spray deposited mercury doped cadmium sulfide thin films. International Journal of Recent Advances in Physics (IJRAP), 2014, 3(1).

[16] Y.A. Kumar, A. Sivasankar, P. Sreedhara, Substrate Temperature Dependent Properties of $\mathrm{Cu}$ Doped $\mathrm{NiO}$ Films Deposited by DC Reactive Magnetron Sputtering. Mater. Sci. Technol. 03, 005, 2013.

[17] E.W. David, Semiconducting Oxides as Gas-Sensitive Resistors. Sensors and Actuators B, 1999, 57: 1-16.

[18] H.H. Afify, I.K. Battisha, Oxygen interaction with CdS based gas sensors by varying different preparation parameters. Journal of Materials Science: Materials in Electronics, 2000, 11(4): 373-377.

[19] B.T. Raut, P.R. Godse, S.G. Pawar, et al., Novel method for fabrication of polyaniline-CdS sensor for $\mathrm{H}_{2} \mathrm{~S}$ gas detection. Measurement, 2012, 45: 94-100.

[20] A. Giberti, D. Casottia, G. Cruciani, et al., Electrical conductivity of CdS films for gas sensing: Selectivityproperties to alcoholic chains. Sensors and Actuators B, 2015, 207: 504-510.

[21] R.K. Sonker, B.C. Yadav, V. Gupta, et al., Synthesis of CdS nanoparticle by sol-gel method as low temperature $\mathrm{NO}_{2}$ sensor. Materials Chemistry and Physics, 2020, 239: 121975.

[22] R. Elilarassi, S. Maheshwari, G. Chandrasekaran, structural and optical characterization of cds nanoparticles synthesized using a simple chemical reaction route. Optoelectronics and Advanced Materials-Rapid Communications, 2010, 4(3): 309-312.

[23] Y. Hu, B. Wang, J. Zhang,et al., Synthesis and photoelectrochemical response of CdS quantum dotsensitized $\mathrm{TiO}_{2}$ nanorod array photoelectrodes. Nanoscale Res Lett, 2013, 8(1): 222.

[24] P. Roy, S.K. Srivastava, A new approach towards the growth of CdS thin film of CBD method and its characterization. Mater. Chem. Phys., 2006, 95: 235.

[25] A. Monshi, M.R. Foroughi, M.R. Monshi, Modified Scherrer Equation to Estimate More Accurately NanoCrystallite Size Using XRD. World Journal of Nano Science and Engineering, 2012, 2: 154-160.

[26] P. BinduEmail, S. Thomas, Estimation of lattice strain in $\mathrm{ZnO}$ nanoparticles: X-ray peak profile analysis. $J$ Theor Appl Phys., 2014, 8: 123-134.

[27] R. Koole, E. Groeneveld, D. Vanmaekelbergh, book, Chapter 2 Size Effects on Semiconductor Nanoparticles. Springer-Verlag Berlin Heidelberg, 2014.

[28] S. Maeng, $\mathrm{SnO}_{2}$ Nanoslab as $\mathrm{NO}_{2}$ Sensor: Identification of the $\mathrm{NO}_{2}$ Sensing Mechanism on an $\mathrm{SnO}_{2}$ Surface. American Chemical Society. Appl. Mater. Interfaces, 2014, 6: 357-363.

[29] A. Szychowska, M. Wróbel-Jędrzejewska, I. Chylak, et al., "Investigation of $\mathrm{CO}$ Oxidation by NO with Application of Semiconductor Gas Sensors. Polish J. of Environ. Stud., 2008, 17(3): 421-425.

[30] V. Orghese, O.K., C.A. Geimes, Metal Oxide Nanostructures as Gas Sensor." Encyclopedia of Nanoscience and Nanotechnology. American Scientific Publishers, USA, 2011: 505-521.

[31] M. Amir, Y. Hou, Evolution of Hydrogen Gas Sensing Properties of Sol-Gel Derived Nickel Oxide Thin Film. Sensors and Actuators Journal, 2013, 182: 125-133.

Copyright $\left({ }^{C}\right.$ Ehssan Salah Hassan, Zaid Saud Razzaq, Huda Ashur Shati Qutbi, Sami Salman Chiad, Nadir Fadhil Habubi, and Khalid Haneen Abass. This is an open-access article distributed under the terms of the Creative Commons Attribution License, which permits unrestricted use, distribution, and reproduction in any medium, provided the original author and source are credited. 